\title{
Studying the expression rate and methylation of Reprimo gene in the blood of patients suffering from gastric cancer
}

\author{
Amin Abbasi (1), Sahar Heydari (2) \\ (1) Department of Biology, East Tehran Branch, Islamic Azad University, Tehran, Iran; (2) \\ Department of genetic, Biology Research Center, Zanjan Branch, Islamic Azad University, \\ Zanjan, Iran \\ This article is distributed under the terms of the Creative Commons Attribution Noncommercial License (CC BY-NC 4.0) which permits \\ any noncommercial use, distribution, and reproduction in any medium, provided the original author(s) and source are credited.
}

\begin{abstract}
As gastric cancer has no exclusive signals in its initial phases, it is usually diagnosed in advanced phases. Although many researches have been conducted on methylation and diagnosis of cancer's markers, the methylation and expression of Reprimo gene and its correlation with gastric cancer has not been thoroughly studied. Methylation of Reprimo promoter is a repetitive procedure exclusive to cancer which nullifies its expression and performance. The present research seeks to study the expression and methylation of Reprimo among people suffering with gastric cancer so that it may be used as a biomarker for early diagnosis. Fifty blood samples taken from healthy people (normal samples) and 50 blood samples obtained from gastric cancer patients were analyzed using Real-Time PCR. The methylation status of the promoter of Reprimo was studied using Methylation Specific PCR technique in normal samples and in gastric cancer Iranian patients. We observed reduction in expression rate of Reprimo in the blood samples of patients suffering with gastric cancer in comparison to normal blood samples. A significant correlation was also observed between the expression rate of this gene, age and methylation of its promoter among patients suffering with gastric cancer and various analysis points to a correlation between reduced expressions of Reprimo gene in gastric cancer patients. In conclusion, reduced expression of Reprimo gene and greater levels of methylation of its promoter seems to be promising biomarkers for early diagnosis of gastric cancer.
\end{abstract}

Key Words: Gastric cancer, methylation, MS-PCR, Reprimo

Eur J Transl Myol 28 (2): 226-232, 2018

Gastric cancer is the 5 th most common type of cancer in the world with a mortality rate of 723000 cases reported in 2012 throughout the world rendering it as the third main cause of mortality as a result of cancer. ${ }^{1}$ Reprimo (RPRM) gene acts as a potential suppressor of P53dependent tumor signaling pathway. It encodes a highly glycosilated protein mostly found in cytoplasm. ${ }^{2,3}$ Reprimo is one of the genes responsible for regulation of development and growth of normal cells. ${ }^{4}$ Deactivation of Reprimo gene usually takes place in initial phases of various tumors mostly as a result of DNA methylation. ${ }^{5}$ It has been greatly observed that in two cell categories of gastric cancer without Reprimo methylation, weak expression in normal conditions and high expression in cases of DNA damage were observed. ${ }^{6}$ Expression of Reprimo is usually stimulated in response to damages caused to DNA, but expression of Reprimo wipes out the expression and effects of this gene. ${ }^{6,7}$ As a result, this gene acts as a suppressive agent for tumor growth in gastric cancer. Clinical assessment of methylation of Reprimo promoter may be used as an indicator of invasive tumors, and thus as an indicator for chemotherapy. ${ }^{8}$ Although it is of significant importance for better management of gastric cancer, the methylation and expression of Reprimo gene and its correlation with gastric cancer has not been thoroughly analyzed. Thus, the present research seeks to study the correlation between methylation and expression rate of Reprimo gene in gastric cancer.

\section{Materials and Methods}

The present research studied as many as 100 venous blood samples including 50 healthy blood samples (normal samples) and 50 blood samples obtained from gastric cancer patients. Proper samples were obtained from Masoud Medical Diagnostic Laboratory (Iran) collected from 2013 to 2015 in test tubes containing EDTA. The individuals studied aged 16 to 86 years old. 
Table 1. Primers designed for Real-Time PCR reaction of Reprimo and GAPDH genes

\begin{tabular}{cccc}
\hline Primer & Sequence & Tm ${ }^{\circ} \mathrm{C}$ & Amplicon Size (bp) \\
\hline Reprimo (F) & CTGGGACAAAGACCCAGAAT & 58.99 & $83 \mathrm{bp}$ \\
Reprimo (R) & GGTGTCACGGATGTCAAGAG & 59.10 & $83 \mathrm{bp}$ \\
GAPDH (F) & ATGGAGAAGGCTGGGGCT & 62.05 & $124 \mathrm{bp}$ \\
GAPDH (R) & ATCTTGAGGCTGTTGTCATACTTCTC & 61.62 & $124 \mathrm{bp}$ \\
\hline
\end{tabular}

Table 2. Primers designed for methylated and non-methylated regions in MS-PCR reaction

\begin{tabular}{lccc}
\hline \multicolumn{1}{c}{ Primer } & Sequence & Tm ${ }^{\circ} \mathrm{C}$ & $\begin{array}{c}\text { Amplicon } \\
\text { Size }(\mathrm{bp})\end{array}$ \\
\hline ReprimoMet (F) & AGTATTATTAGGGTTGGAGCGGACG & 61.2 & $158 \mathrm{bp}$ \\
Reprimo Met (R) & AAATACCGAACTAAACGCTCACTCG & 60.7 & $158 \mathrm{bp}$ \\
Reprimo Unmet (F) & TATTATTAGGGTTGGAGTGGATG & 54.3 & $158 \mathrm{bp}$ \\
Reprimo Unmet(R) & AAATACTGAACTAAATGCTCACTTG & 55.2 & $158 \mathrm{bp}$ \\
\hline
\end{tabular}

Twentysix samples were from female and the remaining sevetyfour from male subjects. 40 samples were older than 55 years, while the remaining 60 were younger than 55. All participating patients in this study were in the early stages of gastric cancer. They had been referred to the doctor with stomach ache, diarrhea and vomiting.

Extracting RNA from blood and cDNA synthesis

RNA extraction kit of Kiagen Com. (cat. No. 762165) was used to extract RNA in accordance with the standard

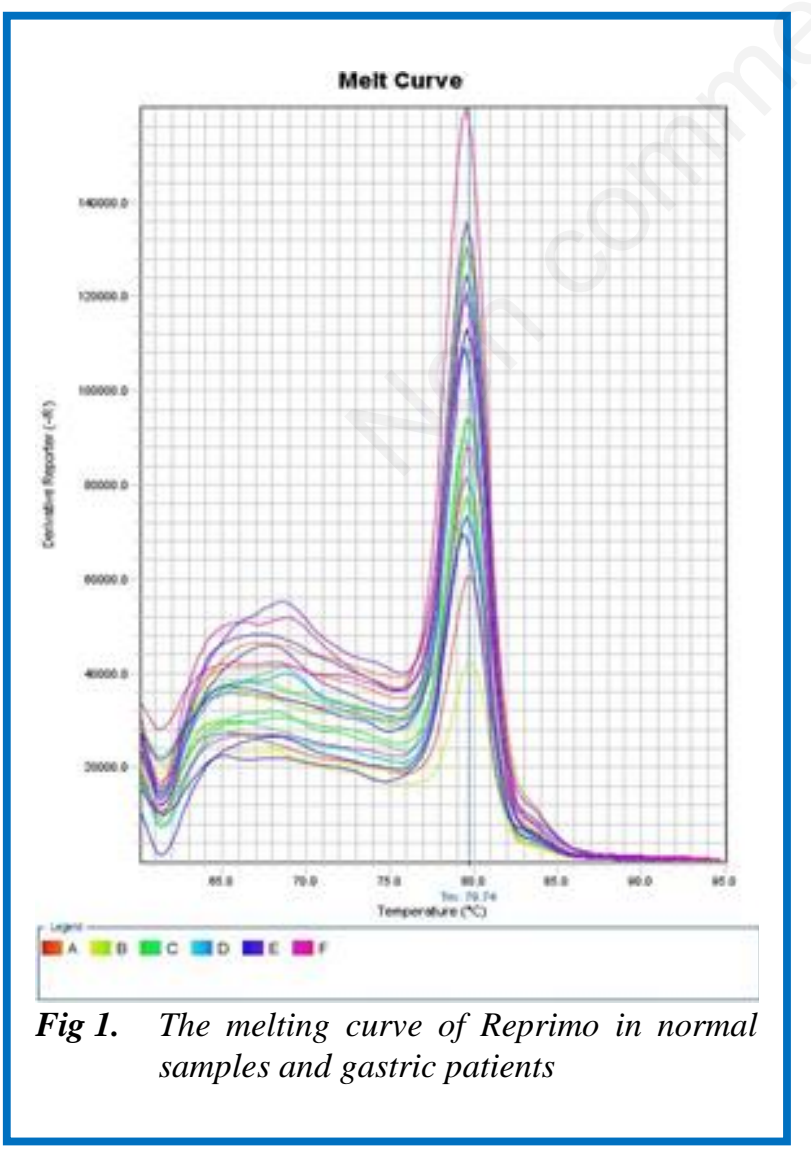

protocol which accompanied the kit. cDNA synthesis was carried out in a microtube $1 \mu \mathrm{l}$ of dNTP $(10 \mathrm{Mm}), 1 \mu \mathrm{l}$ of Random Hexamer (400Mm), $1 \mu \mathrm{l}$ of Oligo dt, $2 \mu \mathrm{l}$ of MMULV 10X buffer, $0.5 \mu \mathrm{l}$ of MMULV (200U/ $\mu \mathrm{l})$ all provided by Sinagen Co. (Iran) and the $10 \mu \mathrm{l}$ of RNA sample and $4.5 \mu \mathrm{l}$ of Nuclease Free Water in a total volume of $20 \mu \mathrm{l}$ was conducted. The microtubes were exposed to a temperature of $65^{\circ} \mathrm{C}$ for 5 minutes and then to a temperature of $4{ }^{\circ} \mathrm{C}$ for 1 minute. Glyceraldehyde-3-

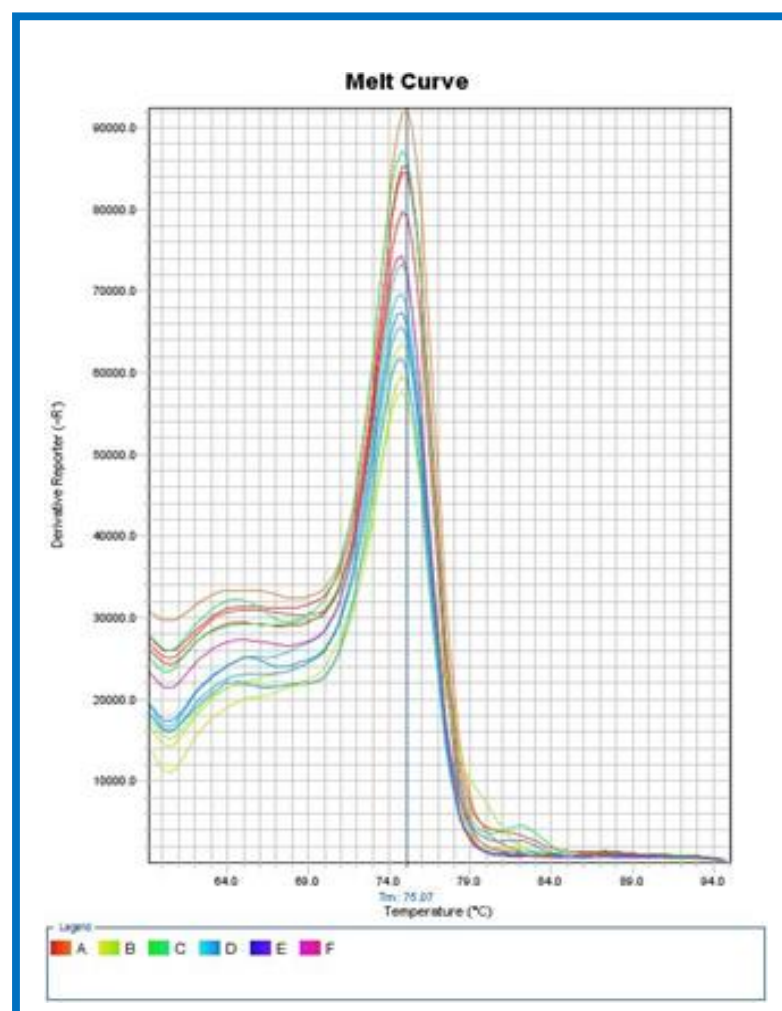

Fig 2. The melting curve of GAPDH gene in normal samples and gastric patients 
Fig 3. Linear curve of Reprimo gene proliferation in normal samples and gastric patients

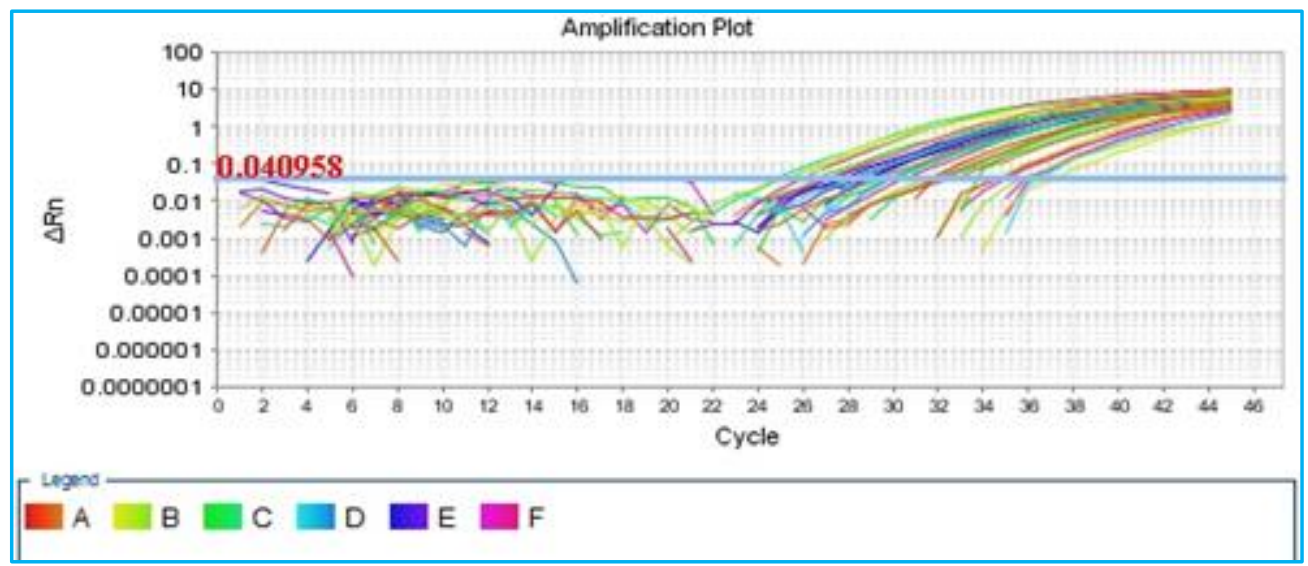

Phosphate Dehydrogenase (GAPDH) was used for internal control.

\section{Carrying out Real-Time PCR}

Using the sequences in NCBI gene bank, the primers required for Reprimo genes and GAPDH were designed and studied using Gene Runner software. The designed primer had a $100 \%$ match with sequences and it was used in Iran for the first time (Table 1). The mixture of RealTime PCR contained $10 \mu \mathrm{l}$ of master mix obtained from Sinagen Co. (Iran), $0.5 \mu \mathrm{l}$ forward primer $(0.4 \mathrm{mM}), 0.5 \mu \mathrm{l}$ of reverse primer $(0.4 \mathrm{mM}), 1 \mu \mathrm{l}$ of cDNA sample, and $8 \mu \mathrm{l}$ of distilled water with a total volume of $20 \mu \mathrm{l}$. The following thermal plan was designed for PCR reaction using Reprimo primer: 10 minutes of initial denaturation in a temperature of $95^{\circ} \mathrm{C}$ for 1 cycle, 40 cycles of exposure to a temperature of $95{ }^{\circ} \mathrm{C}$ each lasting 15 seconds, and 1 minute of exposure to $64.6{ }^{\circ} \mathrm{C}$ of annealing. The following thermal plan was defined for PCR reaction using GAPDH primers as internal controls:
10 minutes of initial denaturation in a temperature of $95^{\circ} \mathrm{C}$ for 1 cycle, 45 cycles of exposure to a temperature of $95^{\circ} \mathrm{C}$ for 15 seconds, 30 seconds of exposure to an annealing temperature of $59^{\circ} \mathrm{C}$. In the end, the analysis of data obtained through Real-Time PCR was carried out based upon the threshold cycle obtained for target and reference genes. The difference between the average of reference $\mathrm{Ct}$ gene and target $\mathrm{Ct}$ gene was calculated as an indicator of $\Delta \mathrm{Ct}$ for both test and control groups. To study the specificity of primers and cyber green fluorescence color and assuring the proliferation of exclusive parts and making sure there are no non-specific particles and Dimer-Primer in PCR product, the melting curve was drawn for Reprimo and GAPDH genes separately using Step One Real-Time PCR Applied Biosystems (Figures 1 and 2). The linear charts of Reprimo and GAPDH genes proliferation curve were drawn by assessing the changes in the fluorescence level using Step One Real-Time PCR Applied Biosystems (Figures 3 and 4).

Fig 4. The linear curve of GAPDH gene proliferation in healthy and gastric patients

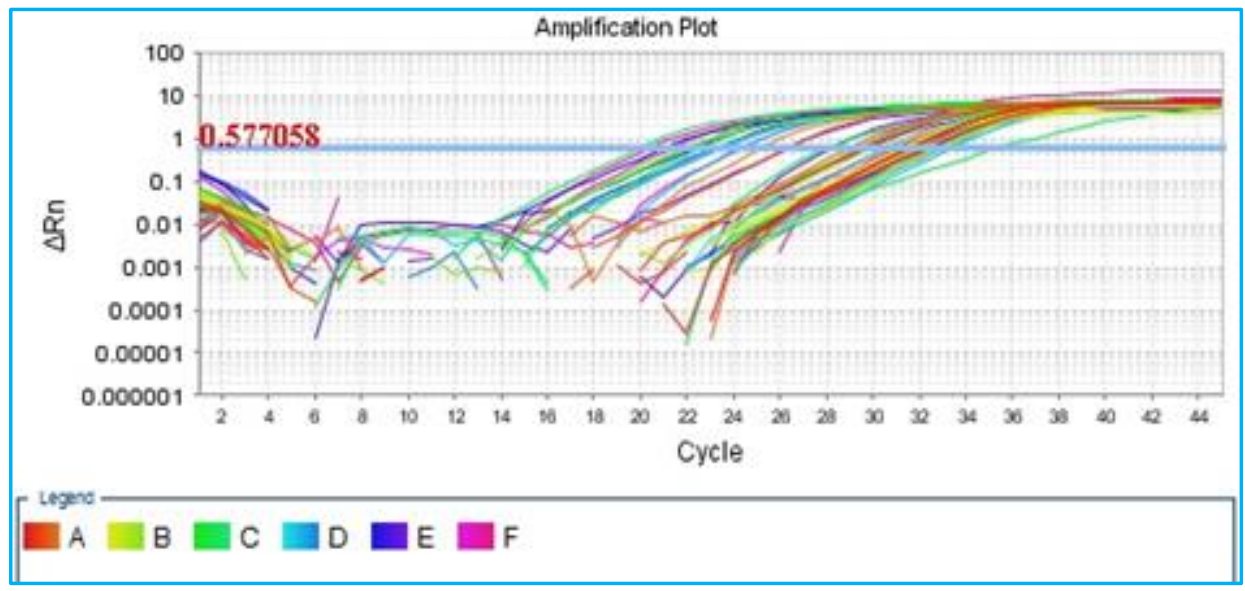




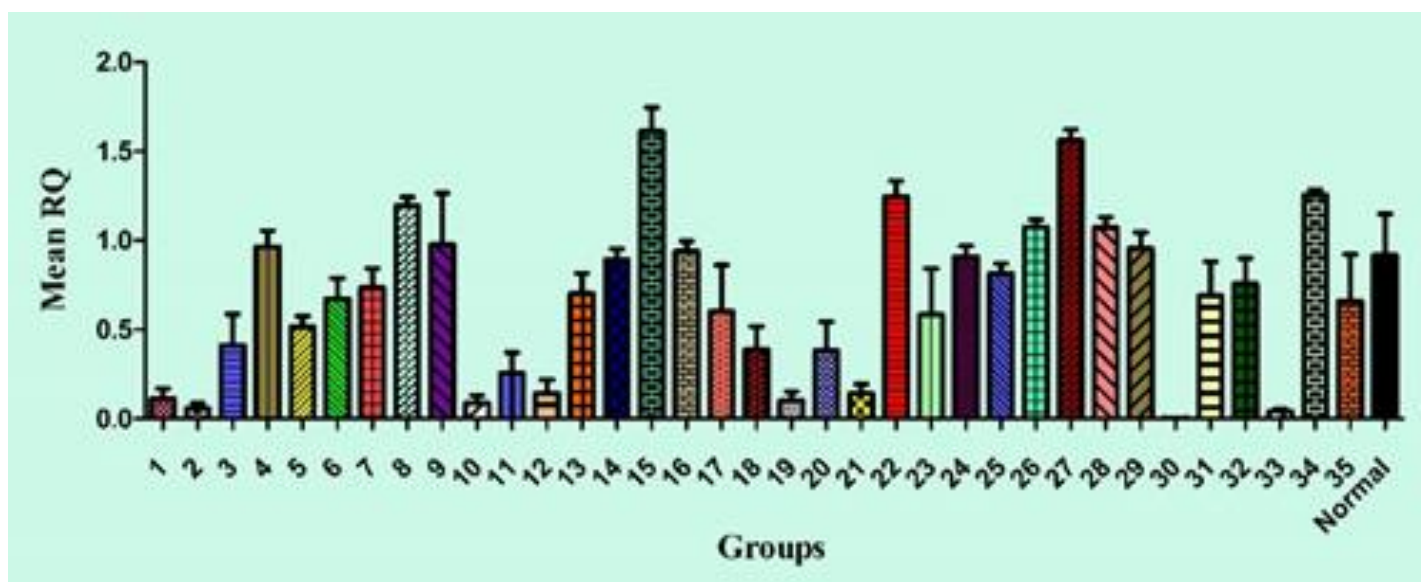

Fig 5. Analysis of Reprimo gene expression in gastric patients compared to normal samples (p-value $\leq 0.0001)$. 1-35 groups: Average rate of Reprimo gene expression in Gastric cancer Patients. Normal group: Average rate of Reprimo gene expression in normal samples.

\section{DNA Modification}

Purification of genome DNA from blood was carried out using DNA purification gene obtained from Kiagen Co. (Cat. No./ID: 69504) based upon the standard protocol specified in the kit. EpiJET Bisulfite Conversion Kit produced by Thermo Scientific Co. (USA) was used for DNA methylation in accordance with the protocol specified in the kit.

\section{MS-PCR to diagnose the methylated and non-methylated areas}

In designing the primers for carrying out MS-PCR (Methylation Specific PCR), those primers designed for the regions containing methylated cytosines begin with letter $\mathrm{G}$, while those designed for areas containing non-

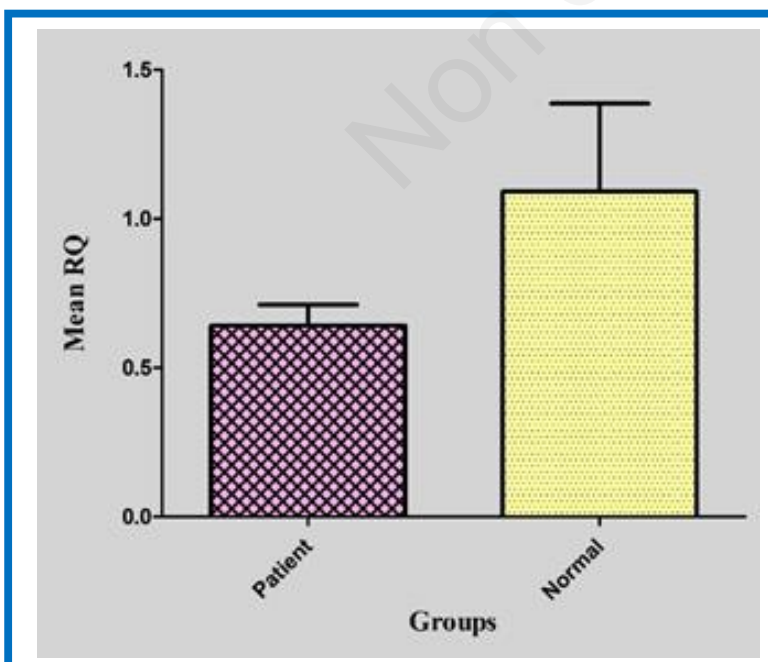

Fig 6. Analysis of Reprimo gene expression rate in gastric patients compared against normal cases $(p \leq 0.04)$ methylated cytosines begin with letter T. Two pairs of primers were designed for this purpose: 1 pair of methylated primer and 1 pair of non-methylated primer (Table 2). The complex used in the reaction contained $12.5 \mu \mathrm{l}$ of master mix produced by Cleaver Scientific in England (Cat. No. CSL-JANDA), $1 \mu 1$ of forward primer, $1 \mu \mathrm{l}$ of reverse primer, $2 \mu \mathrm{l}$ of DNA sample, and $8.5 \mu \mathrm{l}$ of distilled water in a total volume of $25 \mu$. The following thermal plan was defined for MS-PCR in order to diagnose the methylated and non-methylated regions: 3 minutes of initial denaturation in a temperature of $93^{\circ} \mathrm{C}$, 30 cycles of exposure to a temperature of $93^{\circ} \mathrm{C}$ for 30 seconds, and exposure to an annealing temperature of $54.4^{\circ} \mathrm{C}$ for primers designed for non-methylated regions and $64.6^{\circ} \mathrm{C}$ for primers designed for methylated regions for 30 seconds, 30 seconds of exposure to a temperature

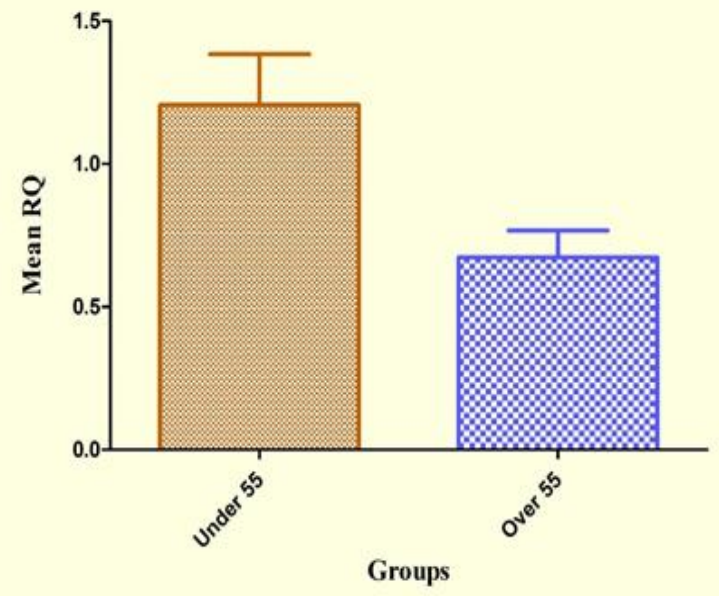

Fig 7. Analysis of expression rate of Reprimo gene among cases older than 55 and those younger than $55(p \leq 0.0106)$ 


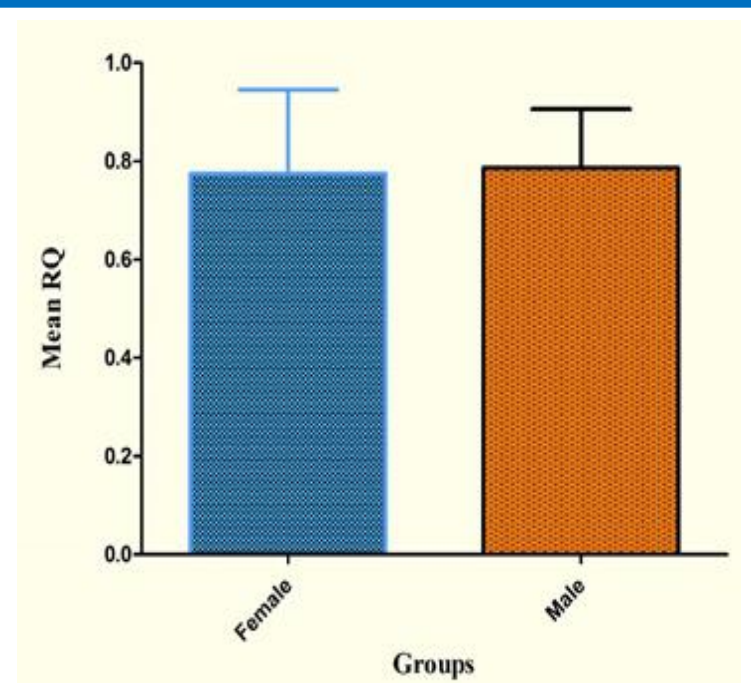

Fig 8. Analysis of expression rate of Reprimo gene among sick cases based upon their gender $(p \leq 0.960))$

of $72^{\circ} \mathrm{C}$ for elongation, and a 1 final cycle of exposure to a temperature of $72^{\circ} \mathrm{C}$ for 5 minutes. Finally, $1.5 \%$ agarose gel was used to study the results of MS-PCR reaction.

\section{Results and Discussion}

The results of the expression rate of Reprimo gene $\mathrm{Ct}$ of samples was calculated by the machine following the proliferation reaction and it was converted to RQ (Quantification Relative) of expression rate. Graph of the results was drawn by Graph Pad Prism software (Fig. 5).

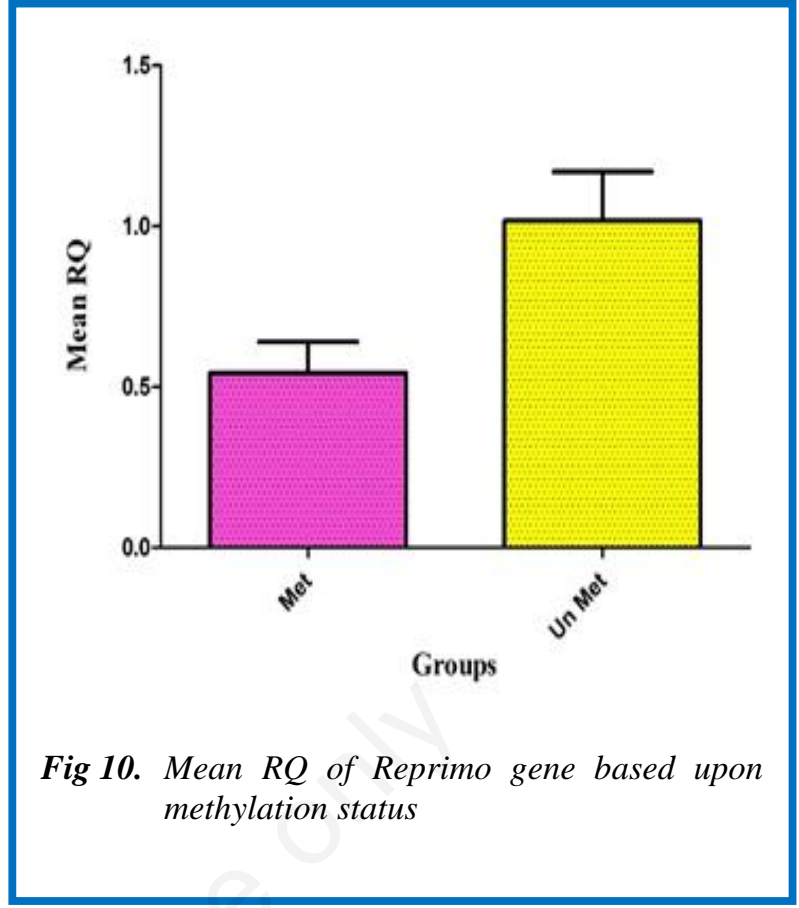

The majority of gastric patients exhibited a reduced Reprimo gene expression rate compared to normal cases. In this case, the average of normal samples was set to 1 by machine analysis. As it was expected from Reprimo Gene as a suppressive tumor in gastric cancer, the expression rate of this gene in normal samples was much more than what was observed in the majority of samples suffering with gastric cancer. This correlation is significant as $\mathrm{P}$-value $<0.05$. The average of expression of gastric patients is much less than what was observed in normal samples. This comparison is a significant correlation considering the p-value (Fig. 10). An analysis

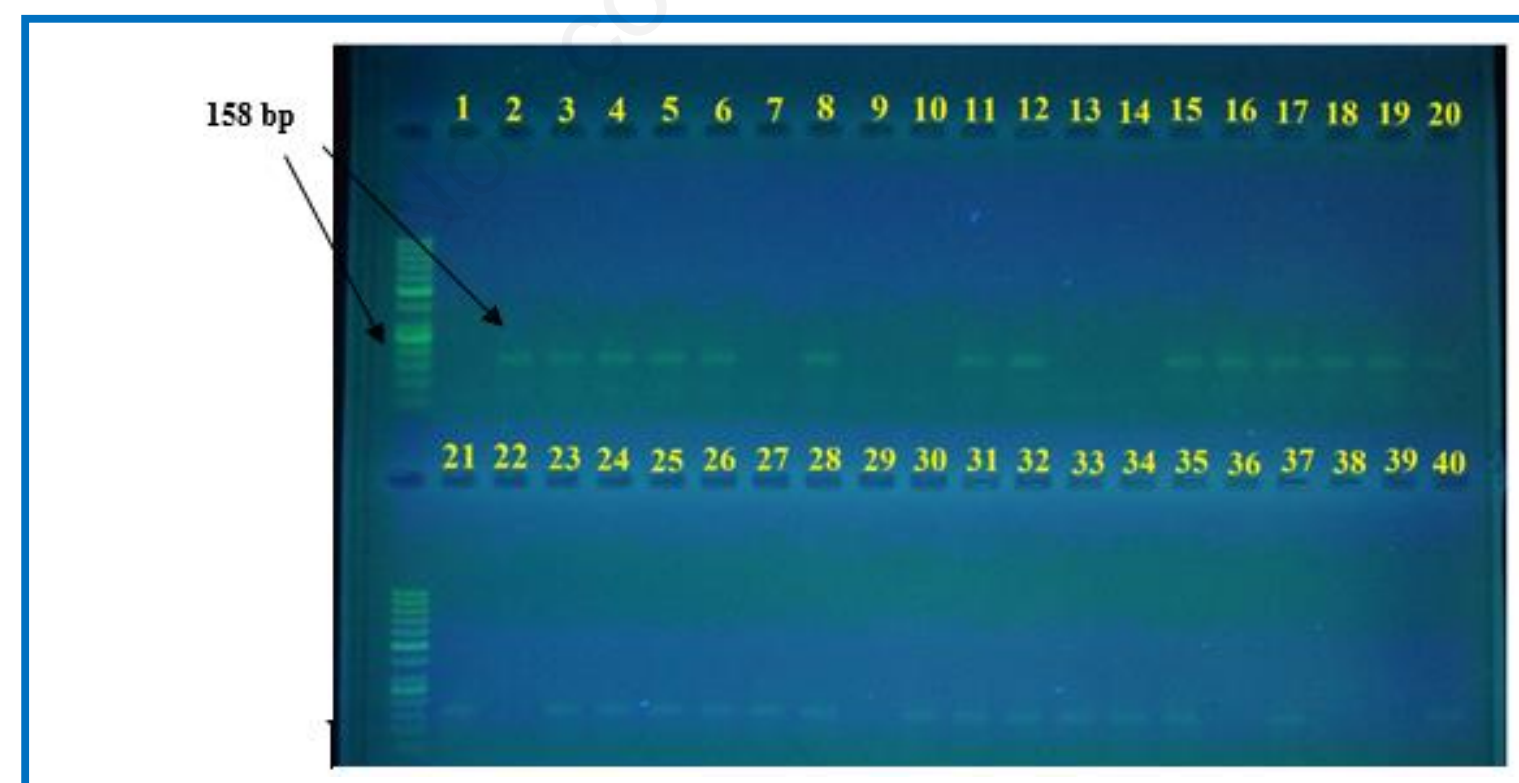

Fig 9. Example of MS-PCR results obtained using methylated primers. The samples with a band size of $158 \mathrm{bp}$ have methylation in the region of Reprimo gene promoter 
of results revealed that the expression rate of Reprimo gene among sick cases compared to healthy people (normal samples) younger than 55 is 1.206 while this value among those older than 55 was 0.673 . This classification is solely based upon people's age group. As it is evident in chart 3 , the mean expression rate of patients younger than 55 is statistically significant (Fig. 7 ). The expression rate of Reprimo gene among male patients was nearly equal to what was observed among female patients and the mean RQ level of men and women was 0.785 and 0.774 respectively (Fig 8). Considering chart 4 , we may conclude that gender has no influence on the expression rate of Reprimo and pathogenicity of gastric cancer.

\section{The results of MS-PCR using methylated primers}

Having carried out MS-PCR using methylated primers on 100 intended samples in order to study the methylation status of Reprimo gene promoter, it turned out that 23 samples out of the total 50 DNA samples of patients were methylated, but this number in normal cases was only 7 . As a result, $45.7 \%$ of samples for Reprimo gene promoter are methylated (Fig. 9). The expression rate of Reprimo gene in non-methylated samples turned out to be $99.6 \%$ while this value in methylated samples was $54 \%$. The mean expression rate of Reprimo gene in non-methylated samples is more than what was observed in methylated samples.

Although recognition of factors such as helicobacter pylori and various environmental factors has helped reduce the prevalence of gastric cancer, it is still one of the most common types of cancers in the world and constitutes a major clinical challenge. ${ }^{9}$ Gastric cancer is one of the most important causes of mortality in developing countries. ${ }^{10}$ As a result of ineffectiveness of most common treatments, the majority of patients have a low survival rate even after treatment and pass away. Various studies have pointed to the fact that various factors such as helicobacter pylori infection and its resulting side effects and other factors such as genetics and its resulting polymorphism may have a major influence on sensitivity and development of gastric cancer. ${ }^{11}$ The multi-factor nature of gastric cancer makes it impossible to come up with an accurate prohibition strategy and to diagnose it quickly. As the majority of gastric cancer cases have no symptoms until they reach the advanced level, early diagnosis of gastric cancer is very difficult. ${ }^{12}$ The first documented epigenetic change in gastric cancer is hyper-methylation of the promoter of genes that restore inconsistent nucleotide mutations of DNA. ${ }^{13}$ Several genes have been described as tumor repressors deactivated as a result of hyper-methylation in gastric cancer. Although recent reports point to the discovery of methylation of particular genes, no comprehensive characteristic of DNA methylation in gastric cancer has been reported to this date. Bernal et al started a research to find a gene with inappropriate hypermethylation which is useful for early diagnosis. ${ }^{15} \mathrm{By}$ searching $\mathrm{CpG}$ islands in the promoter 24 region of candidated gene among 32 cases suffering with gastric cancer, they arrived at the conclusion that inappropriate methylation of Reprimo can act as a potential biomarker for early diagnosis of gastric cancer. Reprimo is the new candidate mediating termination of cell cycle in $\mathrm{G} 2$ phase with the aid of P53. Takao Takahashi et al. have pointed to the fact that Reprimo gene is not expressed by its promoter's methylation in pancreatic and lung cancer. They proved that hyper-methylation is responsible for transcription of Reprimo through hyper-methylation (92\% match). Methylation of Reprimo promoter has been reported in $79 \%$ of gastric cancer, $62 \%$ of gallbladder cancer, $57 \%$ of lymphoma, $56 \%$ of clone cancers, $40 \%$ of esophageal cancer, $37 \%$ of breast cancer, and $31 \%$ of leukemia cases. ${ }^{16}$ By studying 39 patients with an average age of older than 64 and a men to woman ration of 1.3 to 1 and comparing them against normal control samples, Alejandro et al arrived at the conclusion that Reprimo is superior in diagnosing non-invasive genes than CEA and CA 19_9. Sensitivity, specificity, positive predictive value, negative predictive value, and the rate of positive possibilities may be a great progress in assessing the diagnostic effect of Reprimo for noninvasive diagnosis of gastric cancer. ${ }^{17}$ Considering the important effect of Reprimo gene in preventing gastric cancer and as a repressor in early diagnosis of gastric cancer among those suffering with it, we decided to study the expression rate of this gene in the blood sample of those suffering with gastric cancer in Iran. This project is the first comprehensive research studying the expression rate of gene in the blood samples obtained from those suffering with gastric cancer in Iran. Using Real Time PCR based upon cyber-green of RPRM gene expression and utilizing MS-PCR technique, the methylation status of Reprimo gene promoter was studied. As the results of this research showed, the expression rate of RPRM gene in the blood samples obtained from patients is much less than what is observed in normal blood samples. Considering that all patients with gastric cancer who participated in this study were in the early stages of cancer, based on our results, the study of Reprimo gene hypermethylation can be useful in early diagnosis of gastric cancer. Our results are in line with those reported by Kathleen Saavedra et al. pointing that Reprimo gene is a tumor repressor and its methylation in the blood samples obtained from those suffering with gastric cancer is much higer than what we see in healthy individuals (45.7\% of patients constituting a significant correlation). It can also act as a biomarker for early diagnosis of gastric cancer. There is also a significant correlation between expression rate of Reprimo and the age of people suffering with cancer and the methylation status of its promoter. On the hoter hand, the correlation between the expression rate of Reprimo gene and the gender of those suffering with cancer was far from being significant. 


\section{List of acronyms}

MMULV - Moloney Murine Leukemia Virus

MS-PCR - Methylation Specific-PCR

RPRM - Reprimo, TP53 Dependent G2 Arrest Mediator Homolog

RQ - Quantification Relative

\section{Author's contributions}

Each author contributed in equal part to the manuscript.

\section{Acknowledgments}

The authors thank Professors (East Tehran Branch, Islamic Azad University) for their skilled technical assistance.

Funding: None

\section{Conflict of Interest}

The authors declare no conflicts of interests.

\section{Ethical Publication Statement}

We confirm that we have read the Journal's position on issues involved in ethical publication and affirm that this report is consistent with those guidelines.

\section{Corresponding Author}

Amin Abbasi, Department of Biology, East Tehran Branch, Islamic Azad University, Tehran, Iran.

Phone: +989032721145 and +33666942434

Email: aminabbasi1989@yahoo.com

\section{E-mail of co-author}

Sahar Heydari: S.heydari1989@gmail.com

\section{References}

1. Sandoval-Bórquez A, Saavedra K, Carrasco-Avino G, Garcia-Bloj B, Fry J, Wichmann I, Corvalán AH. Noncoding genomics in gastric cancer and the gastric precancerous cascade: pathogenesis and biomarkers. Dis Markers 2015; 2015: 503762.

2. Ikeda F, Doi Y, Yonemoto K, et al. Hyperglycemia increases risk of gastric cancer posed by Helicobacter pylori infection: a population-based cohort study. Gastroenterology 2009;136:1234-41.

3. Baylin SB, Esteller M, Rountree MR, et al. Aberrant patterns of DNA methylation, chromatin formation and gene expression in cancer. Hum Mol Genet 2001;10:687-92.

4. Corvalan AH, Garrido M, Maturana MJ, et al. Su1987 Methylated Reprimo in Cell-Free DNA (RPRM) in Comparison With CEA and CA 19-9 As a Tumor
Marker in Gastric Cancer. Gastroenterology 2015;148:S-568.

5. Costello JF, Frühwald MC, Smiraglia DJ, et al. Aberrant $\mathrm{CpG}$-island methylation has non-random and tumour-type-specific patterns. Nat Genet 2000;24:132.

6. Elimova E, Wadhwa R, Shiozaki H, et al. Molecular biomarkers in gastric cancer. J Natl Compr Canc Netw 2015;13:e19-29.

7. Ohki R, Nemoto J, Murasawa H, et al. Reprimo, a new candidate mediator of the p53-mediated cell cycle arrest at the G2 phase. J Biol Chem 2000;275:22627-30.

8. Ooki A, Yamashita K, Yamaguchi K, et al. DNA damage-inducible gene, Reprimo functions as a tumor-suppressor and is suppressed by promoter methylation in gastric cancer. Mol Cancer Res 2013 Aug 27:molcanres-0091.

9. Saavedra K, Valbuena J, Olivares W, et al. Loss of expression of reprimo, a p53-induced cell cycle arrest gene, correlates with invasive stage of tumor progression and p73 expression in gastric cancer. PLoS One 2015;10:e0125834.

10. Kelley JR, Duggan JM. Gastric cancer epidemiology and risk factors. J Clin Epidemiol 2003;56:1-9.

11. Zhen zhen Z, Si C, Yan Y, et al. Autophagy protects human gastric cancer cells from apoptosis induced by the microtubule-targeting agent Taxol. http://europepmc.org/abstract/cba/646081.

12. Nomura S, Kaminishi M. Surgical treatment of early gastric cancer, Digestive surgery 2007;24:96-100.

13. Shijian F, Li D, Wenbing Z, et al. Histology of stomach and liver in Silurus meridionalis and their change during starvation. Xinan Shifan Daxue Xuebao 1999;24:336-42.

14. Sullivan KD, Gallant-Behm CL, Henry RE, et al. The p53 circuit board. Biochim Biophysica Acta (BBA)Reviews on Cancer 2012;1825:229-44.

15. Bernal C, Aguayo F, Villarroel C, et al. Reprimo as a potential biomarker for early detection in gastric cancer. Clin Cancer Res 2008;14:6264-9.

16. Takahashi T, Suzuki M, Shigematsu H, et al. Aberrant methylation of Reprimo in human malignancies. Int J Cancer 2005;115:503-10.

17. Anderson WF, Camargo MC, Fraumeni JF, et al. Age-specific trends in incidence of noncardia gastric cancer in US adults. Jama. 2010;303:1723-8.

Submission: 19/03/18

Revisions received: 31/05/18

Acceptance: $31 / 05 / 18$ 